\title{
Review on FGM: A Debate on Cultural Diversity and Human Rights Violation
}

\author{
Xiaolu Ni \\ School of Law, Xiamen University, Xiamen 361005, China \\ nixiaolu2013@163.com
}

\begin{abstract}
FGM is a cultural practice lasting for more than 2000 years. Though FGM-supporters justify their action with cultural and social reasons, FGM still violates the human rights of women in nature. With the awareness of women's human rights around the world, numerous measures have been taken to fight against FGM, including legislation, education and NGOs' activities. Although it is difficult to eradicate FGM in the short term, there are still much efforts can be made to create a better environment for the women in FGM-practicing areas.
\end{abstract}

Keywords: Female Genital Mutilation; Cultural Diversity; Human Rights Violation; Actions against FGM.

\section{Introduction}

Female genital mutilation (FGM) is a cultural practice which derives from Africa since about 2000 years ago. During its long existence, millions of women have deeply suffered from this kind of inhumane and cruel surgery. With the development of feminist movements, numerous women begin to realize that their rights have been severely violated. Gradually, people set out to fight for their rights. So far, many countries have taken measures to eradicate female genital mutilation. Nevertheless, considering the influence of religion and sovereignty, there is still a long way to achieve the goal of the complete elimination of FGM.

\section{FGM: Conflict between Cultural Diversity and Human Rights Violation}

On the one hand, in FGM-practicing areas, FGM is a symbol of cultural diversity, people are entitled to maintain and develop it without any kind of interference. On the other hand, FGM has already been depicted as constituting a serious violation of women's human rights. When these two standpoints conflict with each other fiercely, how can the problem be settled?

\subsection{FGM as A Reflection of Cultural Diversity}

In FGM-practicing areas, FGM has been seen as an indivisible part of their culture which should be protected, while no interference can be practiced by any other countries or communities. Although the harmful effects of FGM are well documented, eradication of this practice has proved difficult. In many countries and communities which practicing FGM, proponents hold the view that the practice is so deeply imbedded in the value system of the communities that its elimination is likely to be seen as an attack on the age-old respected cultural practices and beliefs of the communities. Generally speaking, FGM is performed as a rite of passage to womanhood, marking the transition from childhood to womanhood. It is an ancient practice cloaked in tradition allowing women to identify with their cultural heritage. Cultural implications are the strongest factor supporting the FGM because they are imbedded in the daily lives of these women.

\subsection{FGM as A Violation of Human Rights}

During its notorious long history, FGM poses a very serious violation of women's health in several ways. The influence of FGM on women's health is serious and continuous ranges from repeated urinary infections to death. Due to the harmful impacts FGM has caused to women, according to various international instruments with regard to human rights, it constitutes a serious violation of human rights with no doubt. Firstly, FGM violates women's right to equality and non-discrimination on the basis of sex. Secondly, it violates the right to life and health and constitutes an arbitrary intrusion into one's privacy as well. According to a series of international legal instruments like Covenant on the 
Elimination of All forms of Discrimination against Women (CEDAW), women also have a right to equal protection under the law. Therefore the failure of the governments to enact protective laws is a breach of their rights.

\subsection{The Relation between Cultural Diversity and Human Rights Violation}

It is important to emphasize that cultural rights cannot be invoked or interpreted in such a way as to justify any act leading to the denial or violation of other human rights and fundamental freedom. As such, claiming cultural diversity as an excuse to violate or deny human rights is an abuse of the right to culture. Any attempts to justify such violations on the basis of culture have no validity under international law. Female genital mutilation has thus been widely accepted as a violation of human rights. Though the supporters assert that the action is their cultural tradition, it cannot be seen as reasonable. They are attempting to justify this cruel action under the cover of cultural diversity. This is not fair for thousands of those pathetic women who want to get rid of the FGM. For its notorious 'fame', FGM should be seen as the bad ingredient of their culture, it is not worth of being maintained in the name of cultural diversity. Cultural diversity cannot be taken advantage of supporting the draffy tradition in the name of preserving cultural legacy. Cultural tradition cannot be abandoned arbitrarily only on condition of the respect for human rights. When cultural diversity comes into conflict with human rights, the latter one always should be put in the first place by virtue of human rights' supremacy.

\section{Actions against FGM}

So far, although it is quite difficult to eradicate the practice of FGM, some measures have been taken to accelerate the improvement of the situation of women's human rights. Increasingly more international treaties and conventions have been concluded, so as the domestic legislature. Nonetheless, there are more efforts needed to be made, such as launching educational programs to change the attitudes, beliefs and practices of FGM, organizing various specialized communities to promote the elimination of FGM and so forth.

\subsection{Legislation}

The most basic document against FGM is the UN Charter which reaffirms faith in fundamental human rights and the equal rights of men and women. The Universal Declaration of Human Rights specifies that 'all are equal before the law and are entitled without any discrimination to equal protection of the law'. FGM also violates the International Covenant on Economic, social and Cultural Rights and the International Covenant on Civil and Political Rights. Special emphasis should be imposed to the violation of the Convention on the Elimination of All Forms of Discrimination against Women by the FGM. There are various statements in the CEDAW requiring states parties to take actions to protect the equal rights of men and women. This convention provides a strong legal argument justifying the modification of injurious, discriminatory and ancient prejudicial practices such as FGM.

On the other hand, state parties should pass domestic laws to enforce their protection of women' human rights, and spare no efforts to the eradication of FGM. In practice, a few countries have already made some efforts in promoting the legal systems. A number of European countries enacted laws against FGM in 1980s. Many of the African countries have revised their constitutions to prohibit sexual discrimination as well as harmful cultural practices affecting women such as Egypt, Ghana, Ethiopia and Uganda.

\subsection{Education for Change of the Traditional Perceptions}

It is one thing to pass law, but secular disapproval means nothing to individuals who find moral and religious justification for what they do. They believe FGM 'saves and protects' women. Such kind of perceptions is just hard to change. It can only under the constant education, may people realize the negative influence of the FGM gradually and thus start to fight for their own human rights. Consequently, increasing educational opportunities for girls in FGM-practicing countries is an intervention which may have positive results in fighting against FGM. Proper education seems to have 
a direct correlation with discontinuation of FGM. It is necessary for FGM-practicing countries to implement educational programs to alert their citizens to the complications that arise from FGM.

\subsection{Activities of International Communities}

Increasingly more international and national communities and organizations have played important roles in helping changing people's stereotype attitudes and beliefs in the FGM-practicing areas. For example, in Kenya, the Programme for Appropriate Technology in Health (PATH) was designed. The program helped thousands of girls learn the basic knowledge of FGM and other common sense of physical health. In Egypt, there is an organization named Coptic Evangelical Organization for Social Services (CEOSS). In 1990s, this organization began an educational crusade against FGM on a small scale, they carried out their activity by going village to village and began 'development programs aimed at both raising the standard of living ... and at addressing a number of issues' including FGM. In 1998, CEOSS had managed to reduce the number of cases of FGM greatly in 8 villages. In addition to these typical organizations, there are many other communities taking the responsibility of accelerating the elimination of FGM.

\section{Conclusion}

FGM reflects the contradiction between cultural diversity and human rights. In FGM-practicing areas, supporters take this inhumane action as an indivisible part of their culture. Eliminating the FGM amounts to the betrayal of their progenitors. While in civilized society, protecting the fundamental rights of every human being has already been a common sense. No conduct which is against human rights can be tolerated by international society as a whole. On the basis of such theory, FGM has to be eradicated gradually by all countries.

FGM cannot be truly eliminated without changing the societies that practice it. It is necessary to make use of an educative approach so change does not appear to be a mandate from outside. Women need to be supported, educated and involved in the political structure in order to stop FGM. There must be an inherent change in the social position of women. Nonetheless, the structure will not change without pressure from outside. This is the role of international conventions and treaties, international organizations as well. International organizations, NGOs and States operate to raise awareness and consciousness of violations to influence the power structures of those countries and to generate change from within at the grassroots level.

\section{References}

[1]. Leigh A. Trueblood, Female Genital Mutilation: A Discussion of International Human Rights Instruments, Cultural Sovereignty and Dominance Theory, Denver Journal of International Law and Politics, Vol. 28, 2000.

[2]. Michael Ntabaazi, Preventing Female Mutilation Not So Easy, Africa News Service, Aug 3, 1998.

[3]. Christina M. Cerna, Universality of Human Rights and Cultural Diversity: Implementation of Human Rights in Different Socio-Cultural Contexts, Human Rights Quarterly, Vol. 16, No. 4, 1994.

[4]. Female Genital Mutilation: Is it crime or culture? Economist, Feb 13, 1999.

[5]. Information on: http://www.churchworldservice.org/index.html 